\title{
Psychological effects of COVID-19 on children of frontline nurses
}

\author{
Muhammad S. A. Mondal ${ }^{1}$, Humayun Kabir², Md. K. Hasan²
}

\section{AFFILIATION}

1 Department of Biochemistry and Molecular Biology, University of Dhaka, Dhaka, Bangladesh

2 Department of Public Health, North South University, Dhaka, Bangladesh

CORRESPONDENCE TO

Md. K. Hasan. Department of Public Health, North South University,
Dhaka, 1229, Bangladesh. E-mail: kamrul.hasan11@northsouth.edu ORCID ID: https://orcid.org/0000-0002-3032-7640

\section{KEYWORDS}

COVID-19, frontline nurses, mental health of children, parental monitoring

Received: 15 July 2021, Accepted: 23 September 2021

https://doi.org/10.18332/popmed/142558

\section{Dear Editor,}

For the last one and half years, COVID-19 has caused an overwhelming loss of life as a respiratory infectious disease. Based on statistics of physical illness, children are the least affected group. However, that is not the case for mental health. In most cases, nurses and other front liner health workers depend on others like grandparents, relatives, or babysitters, to take care of their children. Due to the closing of schools as a non-pharmaceutical intervention to control COVID-19, youth spend more time on the internet, social media, online gaming, or any such influential addicting technologies ${ }^{1}$. In addition, nurses now have to maintain prolonged quarantine after duty which increases the duration of separation from their family, which can further aggravate the mental health status of their children. These circumstances often are associated with depression, stress, loneliness, and other psychological distressed conditions ${ }^{2}$.

The pandemic has decreased their opportunities for outdoor activities and physical exercise, which is a crucial factor in exacerbating their mental health issues. Closing of educational and social institutes, and emphasis on social distancing, all affect the situation adversely. Such experiences in early childhood are prone to cause a persistent elevation of cortisol and proinflammatory cytokines, resulting in adverse health outcomes later in adult life ${ }^{3}$. Stress can delay cognitive development, increase somatic complaints, worsen obesity, asthma, diabetes, sleep disturbances, recurrent infections, and the list goes on ${ }^{3}$.

Electronic media have played a vital role in rescuing these home-stuck kids from their confinement, but they also have drawbacks. Some have fallen victim to internet and cell phone addiction, facing difficulty readapting everyday life ${ }^{4}$. In several reports, a rise in child abuse has been mentioned while the support system naturally decreased due to the lockdown ${ }^{5}$. All these unexpected events resulted in repercussions such as a tendency to argue, drug addiction, self-harming activities, and sometimes even suicidal thoughts or attempts in the most extreme cases.

Action for change does not require a plethora of changes in the infrastructure, neither demands a large budget. All that is needed are some intervention programs to serve children and caregivers, implemented by the local government. These programs should focus on improving parental skills and responsiveness in understanding children, so as to better protect them from negative experiences. Mentoring the parents can pave the way for developing problem-solving skills in their children, boosting their self-esteem, and helping them to nurture them in the right way to set goals for a promising future ${ }^{6}$. Parents need to monitor children for any signs of change in behavior and act on it patiently, keeping their naivety in mind. Special support from governments is required so that the healthcare professionals can take care of their children and continue their responsibilities during this global crisis.

\section{REFERENCES}

1. Patrick SW, Henkhaus LE, Zickafoose JS, et al. Well-being of Parents and Children During the COVID-19 Pandemic: A National Survey. Pediatrics. 2020;146(4):e2020016824. doi:10.1542/peds.2020-016824

2. Zhu Y, Zhang L, Zhou X, Li C, Yang D. The impact of social distancing during COVID-19: A conditional process model of negative emotions, alienation, affective disorders, and posttraumatic stress disorder. J Affect Disord. 2021;281:131-137. doi:10.1016/j.jad.2020.12.004

3. Oh DL, Jerman P, Silvério Marques S, et al. Systematic review of pediatric health outcomes associated with childhood adversity. BMC Pediatr. 2018;18(1):83. doi:10.1186/s12887-018-1037-7

4. Chen CY, Chen IH, Pakpour AH, Lin CY, Griffiths MD. 
Internet-Related Behaviors and Psychological Distress Among Schoolchildren During the COVID-19 School Hiatus. Cyberpsychol Behav Soc Netw. 2021;10.1089/ cyber.2020.0497. doi:10.1089/cyber.2020.0497

5. Kabir H, Hasan MK, Bhuya MTR. Recommendations for schoolgoing students post CoVid-19 in Bangladesh. Bioinformation. 2021;17(4):500-505. doi:10.6026/97320630017500

6. Escuriet R, Arribas AM, Vélez OC. COVID's collateral damage on women's health: How to resume the path of improvement. Eur J Midwifery. 2020;4(June):1-3. doi:10.18332/ejm/122868

\section{CONFLICTS OF INTEREST}

The authors have completed and submitted the ICMJE Form for Disclosure of Potential Conflicts of Interest and none was reported.

\section{FUNDING}

There was no source of funding for this research.

ETHICAL APPROVAL AND INFORMED CONSENT

Ethical approval and informed consent were not required for this study.

\section{AUTHORS' CONTRIBUTIONS}

All authors have read and approved the manuscript. Conceptualization: HK. Original draft and writing: MSAM and HK. Review and editing: HK and MKH. Investigation: HK and MKH. Data curation, methodology, project administration and validation: $\mathrm{MKH}$.

\section{PROVENANCE AND PEER REVIEW}

Not commissioned; internally peer reviewed. 